\title{
Baroclinic development within zonally-varying flows
}

\author{
David M. Schultz ${ }^{\mathrm{a} *}$ and Fuqing Zhang ${ }^{\mathrm{b}}$ \\ ${ }^{a}$ Cooperative Institute for Mesoscale Meteorological Studies, University of Oklahoma, and National Severe Storms Laboratory, NOAA, USA \\ b Department of Atmospheric Sciences, Texas A\&M University, USA
}

\begin{abstract}
Previous idealized-modelling studies have shown the importance of across-jet barotropic shear to the resulting evolution of cyclones, anticyclones, surface-based fronts, and upper-level fronts. Meanwhile, many observational studies of cyclones have shown the importance of along-jet variations in the horizontal wind speed (i.e. confluence and diffluence). This study investigates the importance of these along-jet (zonal, for zonally-oriented jets) variations in the horizontal wind speed to the resulting structures and evolutions of baroclinic waves, using idealized models of growing baroclinic waves. An idealized primitive-equation channel model is configured with growing baroclinic perturbations embedded within confluent and diffluent background flows. When the baroclinic perturbations are placed in background confluence, the lower-tropospheric frontal structure and evolution initially resemble the Shapiro-Keyser cyclone model, with a zonallyoriented cyclone, strong warm front, and bent-back warm front. Later, as the baroclinic wave is amplified in the stronger downstream baroclinicity, the warm sector of the cyclone narrows, becoming more reminiscent of the Norwegian cyclone model. The upper-level frontal structure develops with a southwest-northeast orientation, and becomes strongest at the base of the trough, where geostrophic cold advection is occurring. In contrast, when the baroclinic perturbations are placed in background diffluence, the lower-tropospheric frontal structure and evolution resemble the Norwegian cyclone model, with a meridionally-oriented cyclone, strong cold front, and occluded front. The upper-level frontal structure is initially oriented northwest-southeast on the western side of the trough, before becoming zonally oriented. Weak geostrophic temperature advection occurs along its length. These results are compared to those from previous observational and idealized-modelling studies. Copyright @ 2007 Royal Meteorological Society
\end{abstract}

KEY WORDS fronts; cyclone life cycles; confluence; diffluence

Received 2 October 2006; Revised 2 February 2007; Accepted 29 March 2007

\section{Introduction}

Despite the tremendous variety in the structure and evolution of extratropical cyclones, there are just two dominant conceptual models of low-level cyclone structure and evolution: the Norwegian cyclone model and the Shapiro-Keyser cyclone model (Figure 1). The Norwegian cyclone model (e.g. Bjerknes, 1919; Bjerknes and Solberg, 1922) is characterized by a meridionallyoriented cyclone, a relatively strong cold front, and the formation of an occluded front by the narrowing of the warm sector as the cold front approaches the warm front (Figure 1(a)). In contrast, the Shapiro-Keyser cyclone model (Shapiro and Keyser, 1990) is characterized by a zonally-oriented cyclone, a relatively strong warm front, and the formation of a frontal fracture (weaker baroclinicity along the poleward part of the cold front), a frontal T-bone structure (cold and warm fronts nearly perpendicular), a bent-back warm front (enhanced baroclinicity in the equatorward flow to the west of the cyclone centre), and warm seclusion (Figure 1(b)).

\footnotetext{
* Correspondence to: David M. Schultz, Division of Atmospheric Sciences, Department of Physical Sciences, University of Helsinki, and Finnish Meteorological Institute, Erik Palménin Aukio 1, PO Box 503, FI-00101 Helsinki, Finland. E-mail: david.schultz@fmi.fi
}

Many investigators have considered the question of what controls whether a given cyclone more closely fits the Norwegian or the Shapiro-Keyser cyclone model. For example, some have argued that surface friction controls the resulting cyclone type: cyclones over the ocean (lower surface friction) being more likely to possess Shapiro-Keyser-like structures than cyclones over land (e.g. Hines and Mechoso, 1993; Kuo and LowNam, 1994; Thompson, 1995; Rotunno et al., 1998). While this may be true, Schultz et al. (1998, p. 1771) argue that numerical-modelling experiments that only vary the magnitude of surface friction are unable to capture the range of variability observed in extratropical cyclones.

Others have argued that the large-scale flow in which the cyclone is embedded plays a significant role in determining the resulting cyclone structure and evolution. These authors have employed observational (e.g. McCallum and Norris, 1990; Evans et al., 1994; Young, 1995; Hartmann, 1995; Schultz et al., 1998; Simmons, 1999; Shapiro et al., 1999; Sinclair and Revell, 2000; Shapiro et al., 2001; Martius et al., 2007) and idealized numerical-modelling (e.g. Davies et al., 1991; Thorncroft et al., 1993; Wernli et al., 1998; Hartmann and Zuercher, 1998; Schultz et al., 1998) studies to support their arguments. 


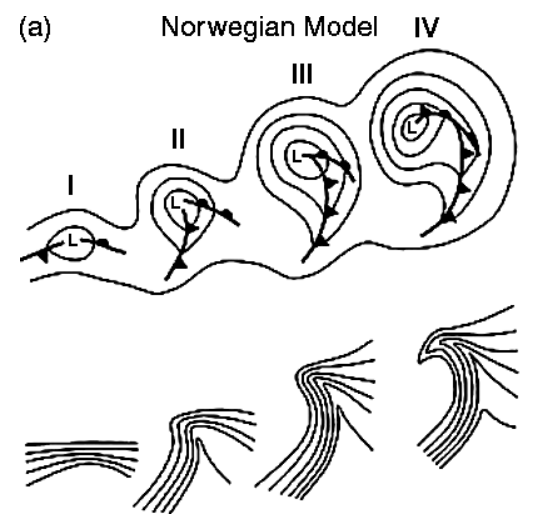

(b) Shapiro-Keyser Model

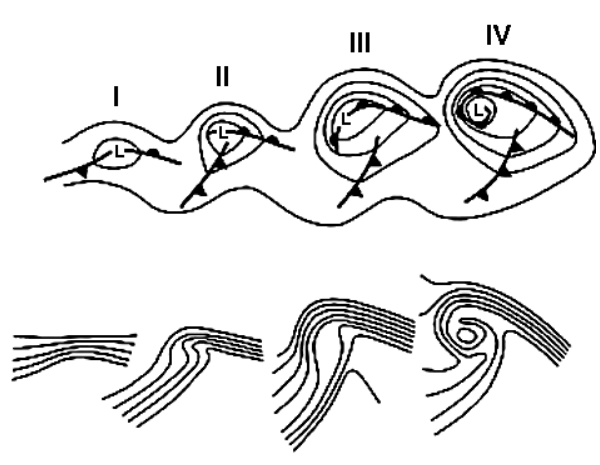

Figure 1. Conceptual models of cyclone evolution showing lower-tropospheric (e.g. $850 \mathrm{hPa}$ ) geopotential height and fronts (top), and lower-tropospheric potential temperature (bottom). (a) Norwegian cyclone model: (I) incipient frontal cyclone; (II, III) narrowing warm sector; (IV) occlusion. (b) Shapiro-Keyser cyclone model: (I) incipient frontal cyclone; (II) frontal fracture; (III) frontal T-bone and bent-back front; (IV) frontal T-bone and warm seclusion. Panel (b) is adapted from (Shapiro and Keyser, 1990, figure 10.27), enhancing the zonal elongation of the cyclone and fronts and reflecting the continued existence of the frontal T-bone in stage IV. The stages in the cyclone evolutions are separated by approximately $6-24 \mathrm{~h}$. The frontal symbols are conventional. The characteristic scale of the cyclones - based on the distance from the geopotential-height minimum, labelled L, to the outermost geopotential-height contour in stage IV - is $1000 \mathrm{~km}$. (Figure and caption from Schultz et al. (1998, figure 15)).

Although many authors agree that the large-scale flow appears to be the dominant factor explaining the differences between the Norwegian and Shapiro-Keyser cyclone models, the exact nature of the large-scale flow required in each case remains disputed. Variations in the horizontal wind speed, either across-jet or alongjet, have been associated with variations in the resulting cyclone structure. We consider below the evidence for how each type of flow affects the cyclone and frontal structure.

Early evidence for the addition of across-jet shear came from Davies et al. (1991), who performed idealizedmodelling experiments using a semi-geostrophic baroclinic channel model on an $f$ plane to show that the addition of a uniform barotropic cyclonic or anticyclonic shear across the jet could affect the cyclone structure. Their control experiment without added shear featured a symmetric, zonal jet in the meridional direction. Baroclinic waves developing in this background state developed a frontal fracture, a bent-back warm front, and a frontal T-bone: features reminiscent of the Shapiro-Keyser cyclone model. When cyclonic shear was added, the baroclinic waves developed a narrowing warm tongue: a feature more associated with the Norwegian cyclone model. When anticyclonic shear was added, the baroclinic waves did not occlude, and the cyclones remained open-wave frontal waves with strong cold fronts, as described by Shapiro et al. (1999).

Thorncroft et al. (1993) performed similar experiments using a primitive-equation model on a sphere. They termed the resulting cyclone life cycle in the control experiment with a nearly-symmetric jet ' $\mathrm{LCl}$ ', and the resulting life cycle in the experiment with added cyclonic shear 'LC2' (also known as cyclonic Rossbywave breaking). Shapiro et al. (1999) later termed the life cycle in the experiment with added anticyclonic shear
'LC3' (also known as anticyclonic Rossby-wave breaking).

Wernli et al. (1998) confirmed that the choice of dynamical framework (semi-geostrophic or primitiveequation) did not materially affect the results. Thus, this body of work suggests that variations in the acrossjet shear result in large-scale deformation that affects the regions of preferred frontogenesis, thus affecting the structure and evolution of baroclinic waves, see Wernli et al. (1998, figure 3) .

A complementary approach is described by Schultz et al. (1998), who argue that zonal variations in the background horizontal wind speed control the structure and evolution of baroclinic waves. They obtain the background flow in these cases quantitatively by filtering the fields into a portion due to the cyclone and a remaining portion attributed to the background flow. They present observational evidence indicating that cyclones moving into a background diffluent flow produce Norwegiantype cyclone structures, whereas cyclones moving into a background confluent flow produce Shapiro-Keysertype structures. Specifically, a background diffluent flow stretches the cyclone in a meridional direction, favouring frontogenesis along the cold front and a more meridionally-oriented warm front. The result is a strong cold front, a weak warm front, and a narrowing of the warm sector to form the occluded front. In contrast, background confluence stretches the cyclones and fronts in a zonal direction, favouring a strong warm front, a weak cold front (especially along its northern extent, the frontal fracture), and the frontal T-bone pattern characteristic of the Shapiro-Keyser model. Furthermore, the advection of the strong warm-frontal temperature gradient around the cyclone favours the development of a bent-back front, and eventual seclusion.

These results are consistent with conceptual models of cyclogenesis determined observationally by Evans et al. (1994), Young (1995), and Sinclair and Revell 
(2000). The fact that jet-entrance and jet-exit regions are favoured regions for cyclogenesis is a strong argument for considering zonal variations in the horizontal wind speed as a possible explanation for cyclone variability.

Schultz et al. (1998) then perform idealized-modelling experiments to demonstrate these differences in cyclone structure and evolution. The experiments are performed by placing a vortex in a background deformation field in a non-divergent barotropic model where potential temperature is treated as a passive tracer. Despite the simplicity of these experiments, they confirm the results from the observational studies showing that confluence and diffluence play a role in affecting lowertropospheric cyclonic and frontal structure and evolution.

In light of these results, an interesting dichotomy becomes apparent. Although nearly all idealized-modelling studies support the across-jet shear paradigm rather than the along-jet shear paradigm for explaining the variations in cyclone structure and evolution, nearly all observational evidence supports the along-jet wind-speed paradigm.

One possible reason for this discrepancy is that the addition of along-jet variability in idealized numerical models is not as simple as the addition of across-jet barotropic shear. Schultz et al. (1998) have shown the feasibility of zonal variability in a barotropic model with potential temperature as a passive tracer, but further experimentation using more sophisticated dynamical frameworks (e.g. semi-geostrophic, primitive-equation) has not been attempted.

A second possible reason is that the degree of acrossjet barotropic shear in observations has not yet been quantified. Indeed, Martius et al. (2007, their section 1) state that, "the understanding of the various interactions among multiple jets and their influence on the life cycles of baroclinic waves is still incomplete." Therefore, the first purpose of the present paper is to show the feasibility of constructing idealized-modelling studies using a primitive-equation model with along-jet variability, demonstrating that differences in cyclone structure and evolution are similar to those previously published.

Variations in upper-level cyclonic and frontal structure have also been examined under different largescale flow patterns. Specifically, the addition of anticyclonic barotropic shear produces positively-tilted troughs (troughs oriented southwest-northeast) with thinning tails at low latitudes. On the other hand, Davies et al. (1991), Thorncroft et al. (1993), Wernli et al. (1998) and Hartmann and Zuercher (1998) have shown that the addition of cyclonic barotropic shear to these idealizedmodelling experiments produces negatively-tilted troughs (troughs oriented northwest-southeast) and a characteristic signature in the upper-tropospheric vorticity field known as compaction (Lackmann et al., 1997). Martius et al. (2007) show the climatological frequency of LC1 and LC2 cyclones (as determined by the upper-level potential-vorticity structures), indicating that the distribution of cyclone structures is sensitive to the large-scale flow pattern.

These evolutions may be compared to those associated with the along-jet variations in wind speed. Specifically, Schultz and Doswell (1999) have examined two types of upper-level frontogenesis occurring over the eastern North Pacific Ocean (Figure 2): those occurring in southwesterly flow and northwesterly flow. Southwesterlyflow upper-level frontogenesis is reminiscent of the situation of a positively-tilted trough (Figure 2(a)), while northwesterly-flow upper-level frontogenesis is reminiscent of the situation of a negatively-tilted trough (Figure 2(b)). Schultz and Sanders (2002) have shown that many trough births in northwesterly flow occur in background flows that are zonally uniform or diffluent. In such flows, the vorticity maximum associated with the developing upper-level front slows down and undergoes compaction because of the downstream diffluence. A corresponding climatology of southwesterly-flow upperlevel fronts has not been attempted. We speculate, however, that such a climatology would favour southwesterlyflow upper-level frontogenesis in confluent background flows, because the large-scale deformation would favour frontogenesis along the confluence downstream of the trough, as the downstream flow accelerates and stretches the front along the flow.

The fact that different modes of upper-level frontogenesis occur in flows with along-jet variability also suggests a link with the conceptual models of lower-tropospheric fronts. Thus, the second purpose of the present paper is to link these conceptual models of upper-level fronts (Figure 2) to the large-scale flow environment, and hence to the conceptual models of lower-tropospheric fronts (Figure 1).

To demonstrate the relationship between the alongjet variations in wind speed, low-level frontal structure, and upper-level frontal structure, we employ idealizedmodel experiments with growing baroclinic waves in background flows with confluence or diffluence. As in the barotropic experiments of Schultz et al., (1998), we abstract cyclones into an idealized framework, allowing feedbacks between the dynamics of the cyclone and the frontal structures and evolutions. The specific model used, and its configuration for the present study, is discussed in Section 2. Section 3 presents the lowertropospheric evolution in these model experiments; Section 4 presents the upper-tropospheric evolution. Finally, Section 5 presents conclusions.

\section{Numerical model, initial conditions, and experimental design}

The idealized experiments are performed with the Pennsylvania State University/National Center for Atmospheric Research (PSU/NCAR) Fifth-Generation Mesoscale Model (MM5) version 2: a non-hydrostatic, primitive-equation model (Dudhia, 1993; Grell et al., 
(a)

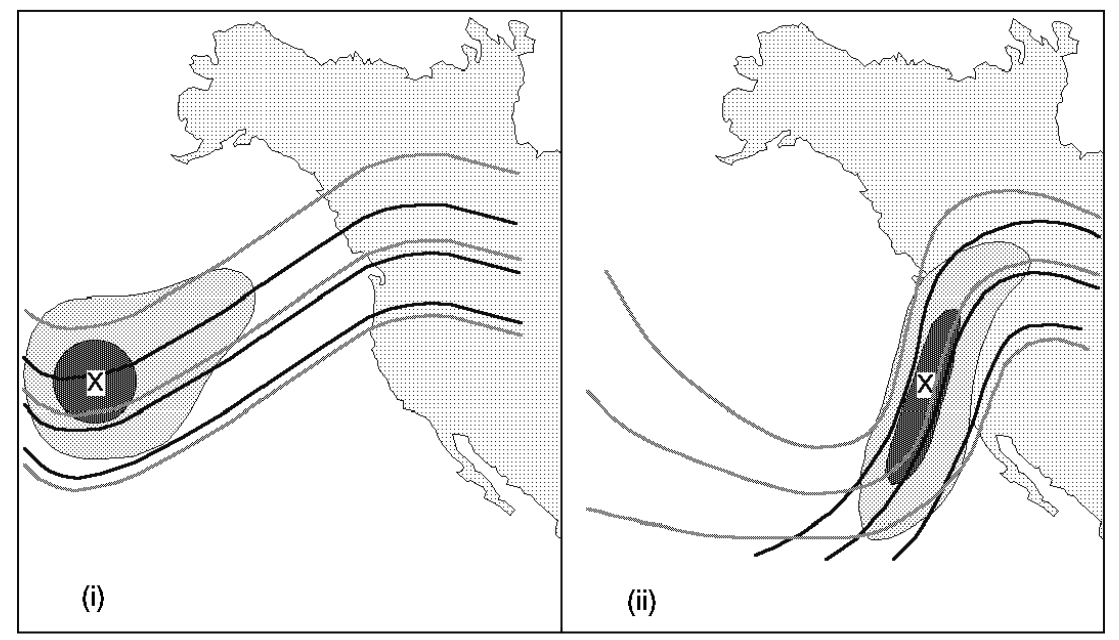

(b)

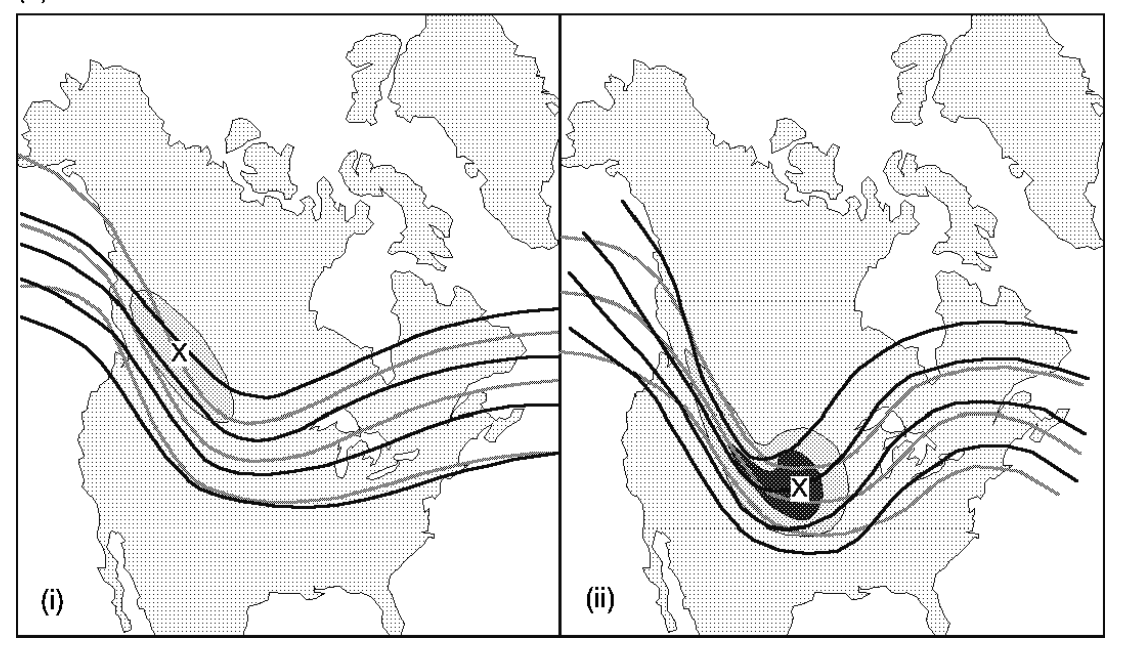

Figure 2. Idealized schematic depiction, on an upper-tropospheric isobaric surface, of the early evolution of an upper-level jet-front system through a mid-latitude baroclinic wave, over 12-24 h. (a) Southwesterly flow. (b) Northwesterly flow. Solid grey lines indicate geopotential-height contours; solid black lines indicate isentropes; shading indicates relative vorticity. X marks the relative vorticity maximum. (Figure and caption from Schultz and Doswell (1999, figure 16)).

1994). The model is configured on an $f$ plane; surface friction, spherical geometry, topography and moist processes are not considered. The model domain extends $25000 \mathrm{~km}$ in the east-west direction and $8000 \mathrm{~km}$ in the north-south direction. We choose such a large domain to minimize the influence of the lateral boundaries on the baroclinic waves. There are 30 vertical layers, and the horizontal grid spacing is $100 \mathrm{~km}$. The upper boundary is set at a constant potential temperature and pressure of $510 \mathrm{~K}$ and $50 \mathrm{hPa}$ respectively. The lateral boundaries are determined by relaxing to an unperturbed and undeveloped background state.

The procedure for creating initial conditions for different experiments is similar to that of Zhang (2004), except that three-dimensional (3D) potential vorticity (PV) inversion is not used. More specifically, a simplified two-dimensional (2D) PV inversion (Davis and Emanuel, 1991 ) is first employed to create a 2D idealized baroclinic jet, as in (Simmons and Hoskins, 1978). We construct two 3D fields, one for a strong jet (maximum wind speed of
$67 \mathrm{~ms}^{-1}$ ) and one for a weak jet (maximum wind speed of $45 \mathrm{~ms}^{-1}$ ). Cross-sections of the two jets after 2D PV inversion are shown in Figure 3. Both strong and weak jets have uniform stratospheric PV of 4.0 PVU and uniform trapospheric PV of 0.5 PVU. The strong jet has a much steeper slope to the tropopause within the jet core. Because the background flow is in thermal-wind balance initially, the strong-jet and weak-jet cases also represent strong and weak baroclinicity, respectively.

The 2D jet is then expanded in the along-jet direction, assuming zonal homogeneity, to create a 3D basic state. The strong and weak jets are joined together with a $3000 \mathrm{~km}$-long transition zone, over which the wind speed varies linearly, to create the initial basic state for a diffluent or confluent jet. Specifically, for the diffluent basic state, the strong jet occupies the western side of the domain $(0-6000 \mathrm{~km}$ in the zonal direction), with a linear decrease in the transition zone $(6000-9000 \mathrm{~km})$, and the weak jet occupies the eastern side of the domain (9000-25000 km). The confluent basic state is 

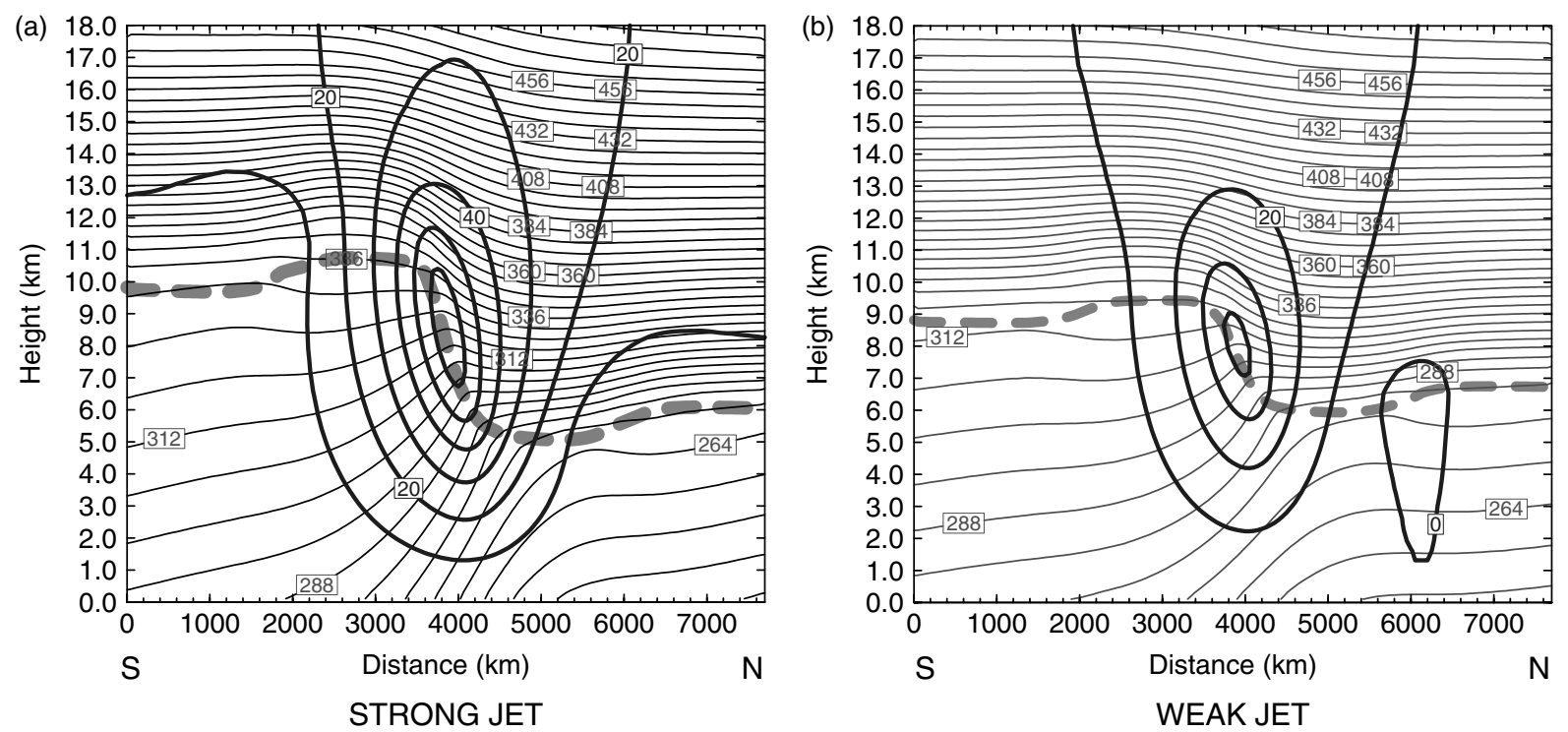

Figure 3. Vertical cross-sections of (a) strong and (b) weak jets: potential temperature (thin solid lines every $6 \mathrm{~K}$ ); wind speed (thick solid lines every $10 \mathrm{~ms}^{-1}$ ); dynamic tropopause (thick dashed line, $1.5 \mathrm{PVU}$ ).

configured similarly, except that the weak jet is in the west and the strong jet is in the east.

A barotropic warm perturbation with a maximum temperature anomaly of $2 \mathrm{~K}$ centred within the jet seeds the baroclinic development for the experiments. The perturbation takes the form of a sinusoidal variation over one zonal wavelength of $3000 \mathrm{~km}$, and cosine-squared variation decreasing to zero in the north-south direction over a distance of $3000 \mathrm{~km}$. The location of the perturbation is chosen so that the growing baroclinic disturbance remains in the transition zone for as long as possible. For the confluent (diffluent) case, the perturbation originates $7500 \mathrm{~km}(6000 \mathrm{~km})$ from the western side of the domain.

Two additional experiments are performed, allowing the basic state to evolve without the barotropic warm perturbations (not shown). These experiments develop baroclinic waves from within the transition zone. However, their development is much slower than the baroclinic waves spawned by the warm perturbations. Consequently, we believe that the development of the baroclinic waves in the confluent and diffluent cases is dominated by the growing warm perturbations being influenced by the large-scale deformation field, rather than by the development of perturbations within the transition zone.

\section{Lower-tropospheric frontal structure and evolution}

In this section, we compare the lower-tropospheric frontal structures and evolutions in the model experiments with confluent and diffluent background flows. One diagnostic we choose for this comparison is the adiabatic Petterssen (1936) frontogenesis function $F_{2}$, the Lagrangian rate of change of the magnitude of the horizontal potentialtemperature gradient due to the horizontal wind:

$$
F_{2}=\frac{\mathrm{d}}{\mathrm{d} t}\left|\nabla_{H} \theta\right|
$$

where

$$
\frac{\mathrm{d}}{\mathrm{d} t}=\frac{\partial}{\partial t}+u \frac{\partial}{\partial x}+v \frac{\partial}{\partial y}
$$

and

$$
\nabla_{H}=\mathbf{i} \frac{\partial}{\partial x}+\mathbf{j} \frac{\partial}{\partial y}
$$

Differentiation on a constant pressure surface is implicit. This expression can be expanded to:

$$
\begin{aligned}
F_{2}= & \frac{1}{\left|\nabla_{H} \theta\right|}\left\{\frac{\partial \theta}{\partial x}\left(-\frac{\partial u}{\partial x} \frac{\partial \theta}{\partial x}-\frac{\partial v}{\partial x} \frac{\partial \theta}{\partial y}\right)\right. \\
& \left.+\frac{\partial \theta}{\partial y}\left(-\frac{\partial u}{\partial y} \frac{\partial \theta}{\partial x}-\frac{\partial v}{\partial y} \frac{\partial \theta}{\partial y}\right)\right\} .
\end{aligned}
$$

This is the sum of terms 2, 3, 6, and 7 in Bluestein (1986, p. $181 ; 1993$, p. 253). Because Petterssen (1936) frontogenesis is related to the horizontal processes promoting the strengthening of a front and the vertical circulation associated with a frontal zone (e.g. Keyser et al., 1988), we use $F_{2}$ to locate the active front on a surface or nearsurface map.

Figure 4 shows the $850 \mathrm{hPa}$ evolution of the experiment with the growing perturbation within background confluence (CONF), from $84 \mathrm{~h}$ into the experiment. The $850 \mathrm{hPa}$ cyclone is initially elongated zonally (Figure 4 (a) and (b)), but as the cyclone deepens rapidly after $96 \mathrm{~h}$, it becomes more circular (Figure 4(c)). The relative cyclonic vorticity also remains primarily zonallyelongated, most strongly along the warm front (Figure 4 (a), (b) and (c)). Throughout the evolution of the cyclone, the warm front remains the strongest front, although the cold front intensifies substantially after $96 \mathrm{~h}$ (Figure 4 (d), (e) and (f)). A well-defined break in frontogenesis occurs along the northern end of the cold front, representing the frontal fracture. The cold front is also nearly perpendicular to the warm front, giving a structure 

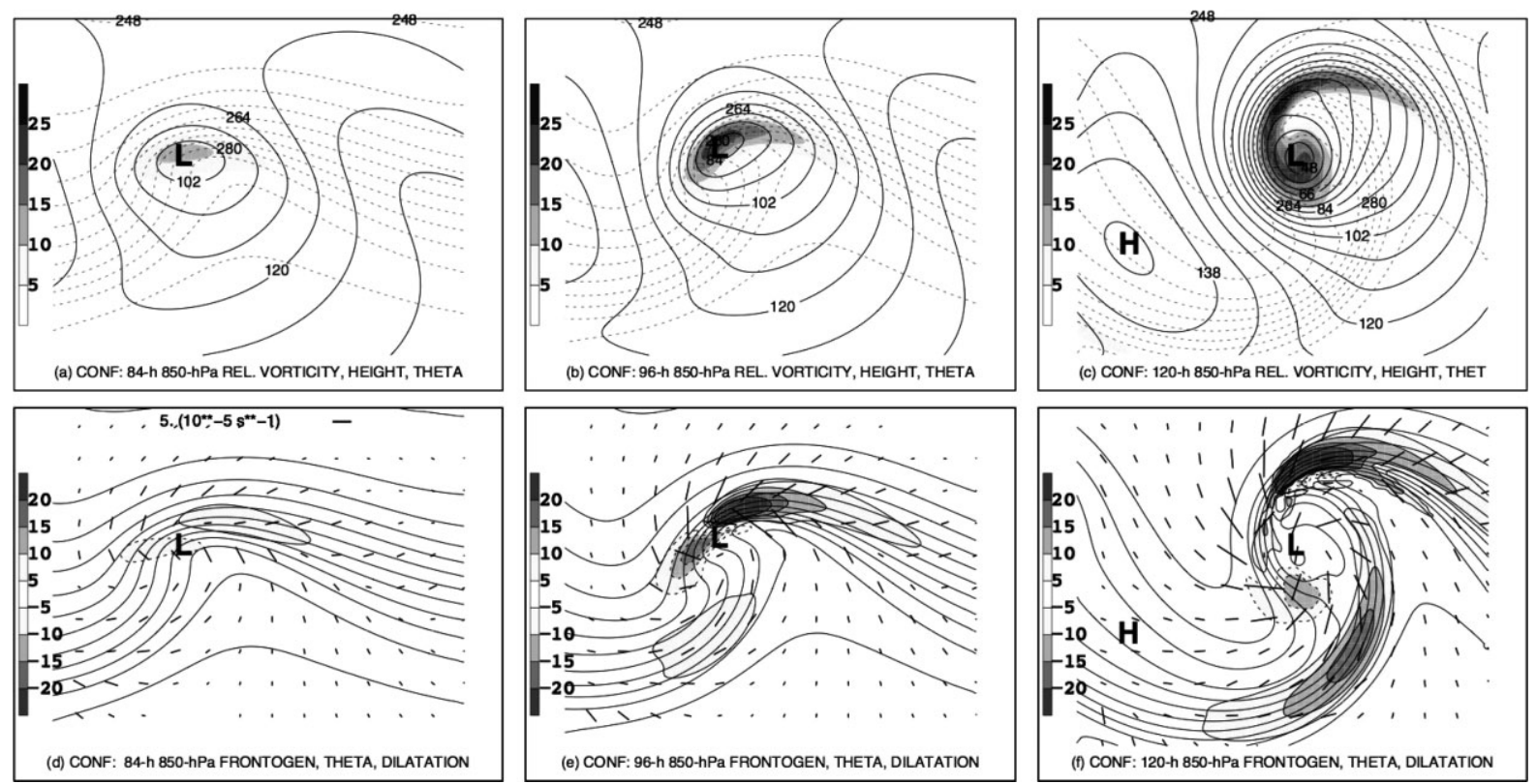

Figure 4. Evolution of a growing baroclinic disturbance in confluent background flow (CONF), at $84 \mathrm{~h} \mathrm{((a)} \mathrm{and} \mathrm{(d)),} 96 \mathrm{~h}$ ((b) and (e)), and $120 \mathrm{~h}((\mathrm{c})$ and (f)). $\mathrm{L}$ and $\mathrm{H}$ indicate locations of minimum and maximum geopotential height, respectively. Only a portion of the computational domain is shown. Top: $850 \mathrm{hPa}$ geopotential height (solid lines every 6 dam); potential temperature (dashed lines every $4 \mathrm{~K}$ ); relative vorticity of the total wind (shaded according to scale in units of $10^{-5} \mathrm{~s}^{-1}$ ). Bottom: $850 \mathrm{hPa}$ potential temperature (solid lines every $4 \mathrm{~K}$ ); Petterssen (1936) frontogenesis due to total horizontal wind $F_{2}$ (contoured and shaded according to scale in units of $10^{-1} \mathrm{~K}(100 \mathrm{~km})^{-1}(3 \mathrm{~h})^{-1}$, positive values solid and negative values dashed); axes of dilatation of total horizontal wind (scale in (d), in units of $10^{-5} \mathrm{~s}^{-1}$, displayed axes of dilatation separated by $300 \mathrm{~km}$ (three grid-point spacings)).
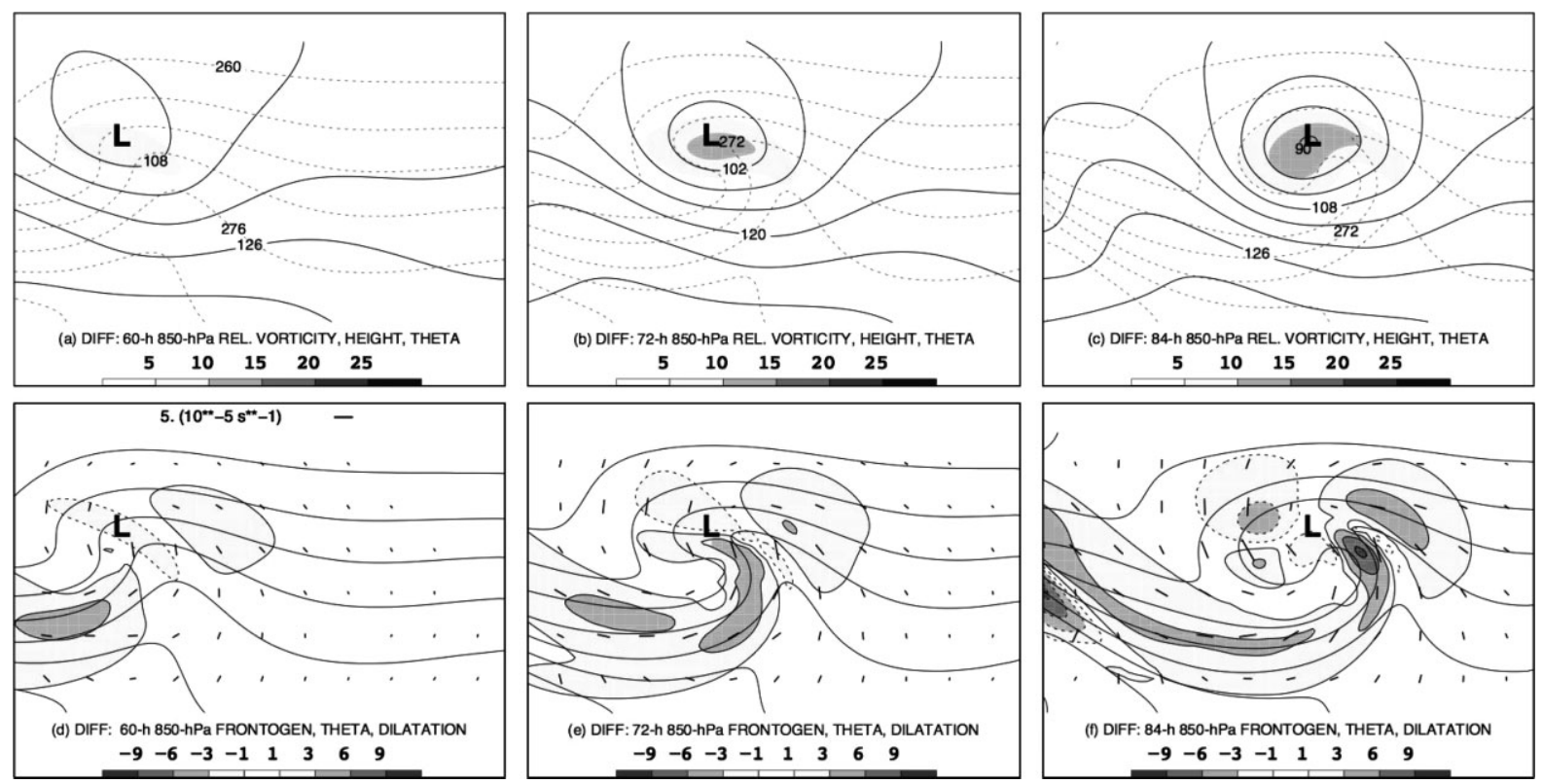

Figure 5. As Figure 4, but for growing baroclinic disturbance in diffluent background flow (DIFF) at $60 \mathrm{~h} \mathrm{((a)} \mathrm{and} \mathrm{(d)),} 72 \mathrm{~h}((\mathrm{~b})$ and (e)), and

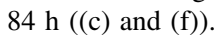

resembling the frontal T-bone described by Shapiro and Keyser (1990). Finally, the baroclinicity associated with the warm front is advected equatorward behind the low centre in the northerly flow, creating a bent-back warm front and warm seclusion (Figure 4(f)). All of these characteristics of the low-level fronts are reminiscent of the Shapiro-Keyser cyclone model, and are consistent with the barotropic-model experiment in confluence performed by Schultz et al. (1998, figure 14).
Figure 5 shows the $850 \mathrm{hPa}$ evolution of the experiment with the growing perturbation within background diffluence (DIFF), from $60 \mathrm{~h}$ into the experiment. The evolution occurs faster than in CONF (note the $12 \mathrm{~h}$ spacing between panels in Figure 5, compared with the $24 \mathrm{~h}$ spacing between panels in Figure 4). The $850 \mathrm{hPa}$ cyclone is initially elongated zonally (Figure 5 (a) and (b)), but as it deepens after $72 \mathrm{~h}$ it becomes more circular (Figure 5(c)). Throughout the evolution of the cyclone, 
the cold front remains the strongest front (Figure 5 (d), (e) and (f)). Unlike in CONF, the northern end of the cold front remains strong near the low centre, even as the cold front and warm front meet, forming a narrowing warm tongue reminiscent of a developing occluded front. These characteristics resemble those of the Norwegian cyclone model, and are consistent with the barotropicmodel experiment in diffluence of Schultz et al. (1998, figure 13).

These results confirm many of the earlier results of Schultz et al. (1998) obtained using a barotropic model with potential temperature as a passive tracer. Specifically, cyclones in confluent background flow develop many of the features of the Shapiro-Keyser cyclone model, while cyclones in diffluent background flow develop many of the features of the Norwegian cyclone model.

One exception is that in the CONF case, the cyclone eventually evolves more Norwegian-like features after about $120 \mathrm{~h}$ (Figure 4(c)), because the baroclinicity allows warm advection to build the ridge and increase downstream diffluence. This is in contrast to the barotropic experiments of Schultz et al. (1998), where no such downstream ridge develops, because the potential temperature in the barotropic experiments is not dynamically active. (Nakamura (1993) finds similar results when cyclonic barotropic shear increases during cyclogenesis: the addition of such shear leads to more Norwegian-like characteristics (e.g. Davies et al., 1991).) Nevertheless, in this respect the original schematic of Shapiro and Keyser (1990, figure 10.27) strongly resembles CONF.

A second exception arises because the cyclones in DIFF and CONF deepen at different rates. The DIFF cyclone develops slightly faster than the CONF cyclone before $84 \mathrm{~h}$ (compare Figures 5(a) and 4(c)). But when the cyclone in CONF reaches the region of stronger baroclinicity downstream, it develops explosively (Figure 4(c)), whereas the DIFF cyclone moves into the weaker baroclinicity and develops less rapidly (not shown). Such baroclinic development does not occur in the barotropic experiments of Schultz et al. (1998).

A third exception is that, because of the thermal-wind balance, the baroclinic zone downstream of the cyclone in CONF is stronger than the baroclinic zone downstream of the cyclone in DIFF (compare Figures 4(d) and 5(d)). This provides initially stronger baroclinicity to feed the warm front in the CONF case, further helping to make the warm front in CONF stronger than the warm front in DIFF (compare Figures 4(f) and 5(f)).

\section{Upper-tropospheric frontal structure}

In this section, we compare the upper-tropospheric frontal structures and evolutions in the model experiments with different background flows. One diagnostic we choose for this comparison is the adiabatic frontogenesis function $F_{3}$, the Lagrangian rate of change of the magnitude of the horizontal potential-temperature gradient due to the $3 \mathrm{D}$ wind. We use the form given by Miller (1948, equation 7) and the adiabatic form of Bluestein (1986, p. 181; 1993, p. 253), except that we use the horizontal rather than the 3D potential-temperature gradient:

$$
F_{3}=\frac{\mathrm{d}}{\mathrm{d} t}\left|\nabla_{H} \theta\right|,
$$

where

$$
\frac{\mathrm{d}}{\mathrm{d} t}=\frac{\partial}{\partial t}+u \frac{\partial}{\partial x}+v \frac{\partial}{\partial y}+w \frac{\partial}{\partial z} .
$$

This expression can be expanded to:

$$
F_{3}=F_{\text {def }}+F_{\text {tilt }},
$$

where

$$
\begin{aligned}
F_{\text {def }}= & \frac{1}{\left|\nabla_{H} \theta\right|}\left\{\frac{\partial \theta}{\partial x}\left(-\frac{\partial u}{\partial x} \frac{\partial \theta}{\partial x}-\frac{\partial v}{\partial x} \frac{\partial \theta}{\partial y}\right)\right. \\
& \left.+\frac{\partial \theta}{\partial y}\left(-\frac{\partial u}{\partial y} \frac{\partial \theta}{\partial x}-\frac{\partial v}{\partial y} \frac{\partial \theta}{\partial y}\right)\right\},
\end{aligned}
$$

and

$$
F_{\text {tilt }}=-\frac{1}{\left|\nabla_{H} \theta\right|} \frac{\partial \theta}{\partial z}\left(-\frac{\partial w}{\partial x} \frac{\partial \theta}{\partial x}-\frac{\partial w}{\partial y} \frac{\partial \theta}{\partial y}\right) .
$$

The term $F_{\text {def }}$, called the deformation term, represents the horizontal processes intensifying the horizontal potentialtemperature gradient. On a constant pressure surface, this term is equivalent to Petterssen (1936) frontogenesis and $F_{2}$ in Equation (1). The term $F_{\text {tilt }}$, called the tilting term, is equivalent to the sum of terms 4 and 8 in (Bluestein, 1986 , p. 181; 1993, p. 253). The tilting term accounts for the role of the vertical motion $w$ in altering the horizontal potential-temperature gradient through tilting of isentropes from horizontal to vertical. Thus, $F_{3}$ as given by Equation (4) can be used to explain how the horizontal gradient of potential temperature is changing instantaneously because of the 3D flow.

Figure 6 shows the $500 \mathrm{hPa}$ evolution of CONF, from $84 \mathrm{~h}$ into the experiment. The $500 \mathrm{hPa}$ vorticity is initially zonally-elongated, in association with the positively-tilted trough (Figure 6 (a) and (b)); but eventually it becomes meridionally-elongated, with the amplification of the baroclinic wave (Figure 6(c)). Along the front, especially in the base of the trough, geostrophic cold advection is occurring, which helps to amplify the upperlevel front, through the Shapiro effect. This is the process whereby both confluence and cold advection act to enhance upper-level frontogenesis: it was studied by Shapiro (1981), Keyser and Pecnick (1985), Keyser et al. (1986) and Reeder and Keyser (1988), and reviewed by Keyser and Shapiro (1986); the term was coined by Rotunno et al. (1994). This upper-level front associated with substantial geostrophic cold advection along its length is consistent with the (Schultz and Doswell, 

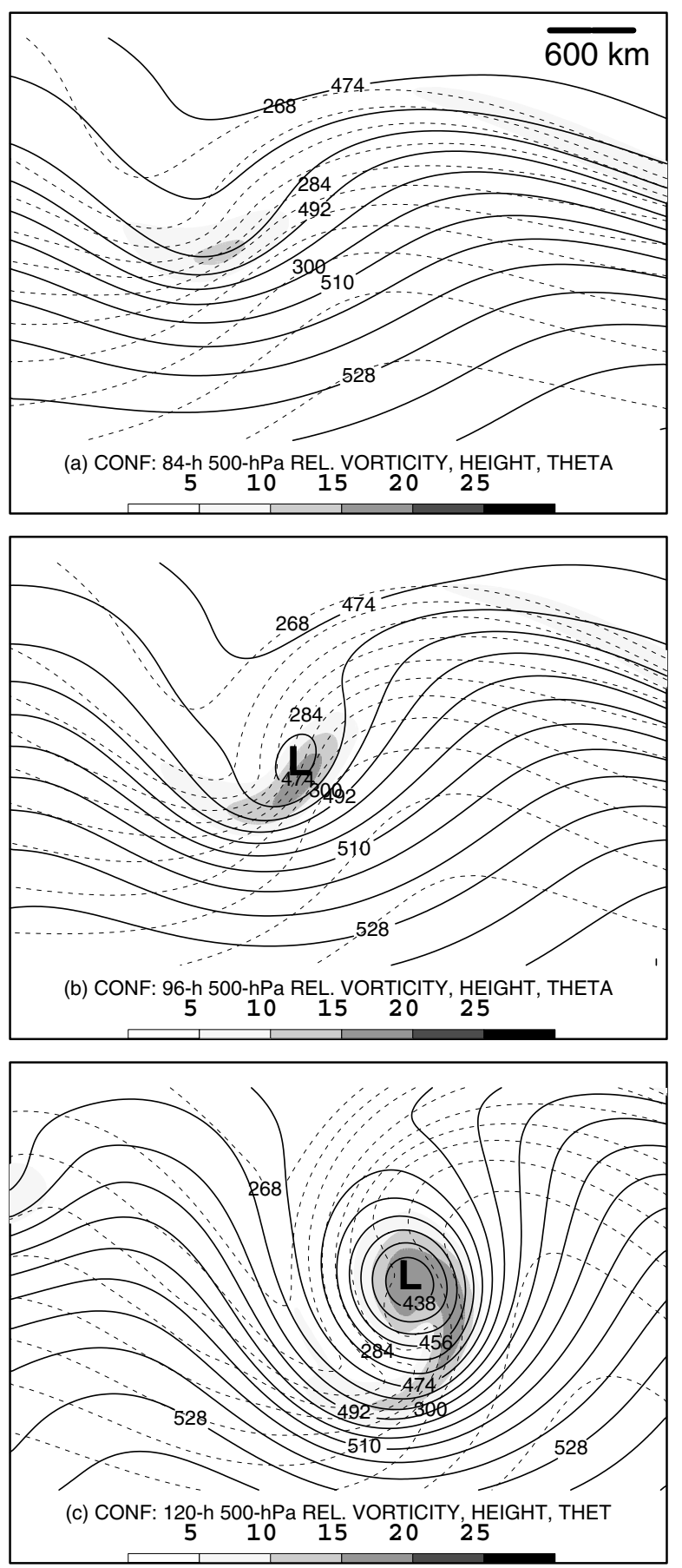

Figure 6. Evolution of a growing baroclinic disturbance in confluent background flow (CONF) at (a) $84 \mathrm{~h}$, (b) $96 \mathrm{~h}$, and (c) $120 \mathrm{~h}$. L and $\mathrm{H}$ indicate locations of minimum and maximum geopotential height, respectively. Only a portion of the computational domain is shown. $500 \mathrm{hPa}$ geopotential height (solid lines every 6 dam); potential temperature (dashed lines every $4 \mathrm{~K}$ ); relative vorticity of the total wind (shaded according to scale in units of $10^{-5} \mathrm{~s}^{-1}$ ).

1999) conceptual model of southwesterly-flow upperlevel frontogenesis (Figure 2(a) (ii)).

In contrast, Figure 7 shows the $500 \mathrm{hPa}$ evolution of DIFF from $60 \mathrm{~h}$. The $500 \mathrm{hPa}$ vorticity is initially elongated along a northwest-southeast axis, in association with the negatively-tilted trough (Figure 7 (a) and (b)). As the system evolves, the vorticity rolls up in

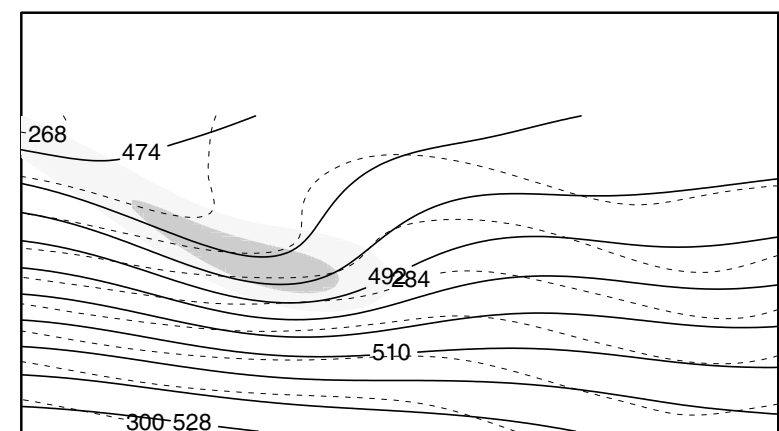

(a) DIFF: 60-h 500-hPa REL. VORTICITY, HEIGHT, THETA
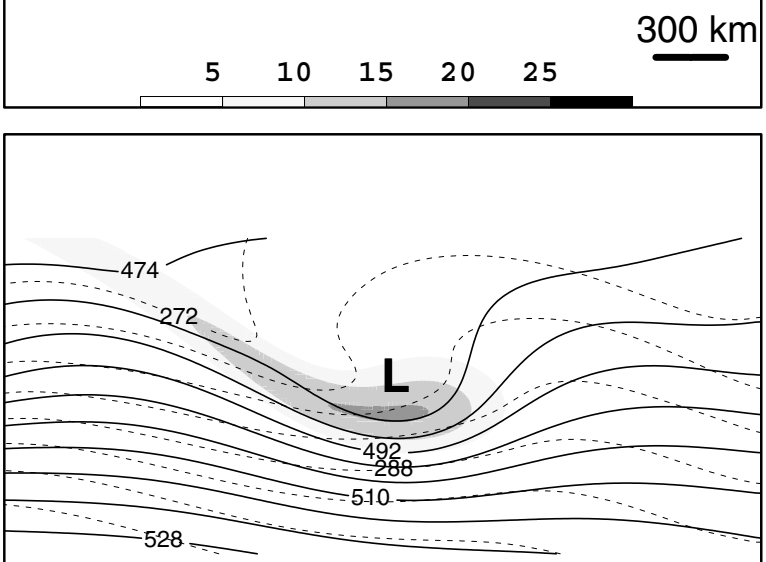

(b) DIFF: 72-h 500-hPa REL. VORTICITY, HEIGHT, THETA
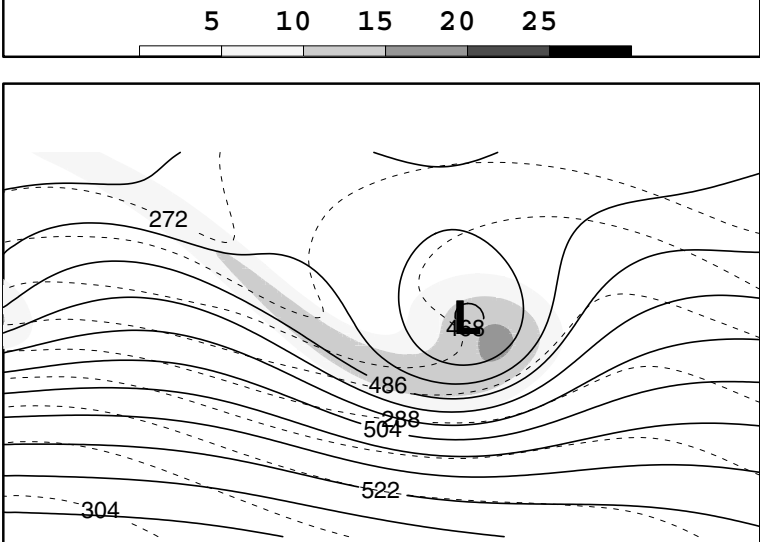

(c) DIFF: 84-h 500-hPa REL. VORTICITY, HEIGHT, THETA

$$
\begin{array}{lllll}
5 & 10 & 15 & 20 & 25
\end{array}
$$

Figure 7. As Figure 6, but for growing baroclinic disturbance in diffluent background flow (DIFF) at (a) $60 \mathrm{~h}$, (b) $72 \mathrm{~h}$, and (c) $84 \mathrm{~h}$.

the base of the $500 \mathrm{hPa}$ trough, as the trough develops closed $500 \mathrm{hPa}$-height contours (Figure 7(c)). The strongest geostrophic cold advection occurs in the base of the trough.

In both cases, but especially in DIFF, the evolution of the vorticity is reminiscent of the compaction process for upper-tropospheric cyclogenetic precursors described by Lackmann et al. (1997). In addition, the deeper $500 \mathrm{hPa}$ low centre after $96 \mathrm{~h}$ in CONF is consistent with the deeper surface low (compare Figures 6(c) and 4(c)). This upper-level frontogenesis in northwesterly flow is 
consistent with the Schultz and Doswell (1999) conceptual model of northwesterly-flow upper-level frontogenesis (Figure 2(b)).

The evolution of the $500 \mathrm{hPa}$ fronts and the terms in Equation (4) are shown for CONF and DIFF in Figures 8 and 9 respectively. In CONF, positive $F_{\text {def }}$ occurs primarily near the base, and slightly to the west, of the trough (Figure 8 (c) and (d)). Tilting frontogenesis $F_{\text {tilt }}$ forms an asymmetric dipole (frontogenesis exceeding frontolysis in magnitude) across the $F_{\text {def }}$ maximum (Figure 8 (e) and (f)), so that the total frontogenesis $F_{3}$ occurs primarily in the base, and on the eastern side, of the trough during cyclogenesis (Figure 8(a) and (b)). Consequently, both $F_{\text {def }}$ and $F_{\text {tilt }}$ contribute to the total frontogenesis along the upper-level front. Maxima of deformation frontogenesis and of tilting frontogenesis overlap
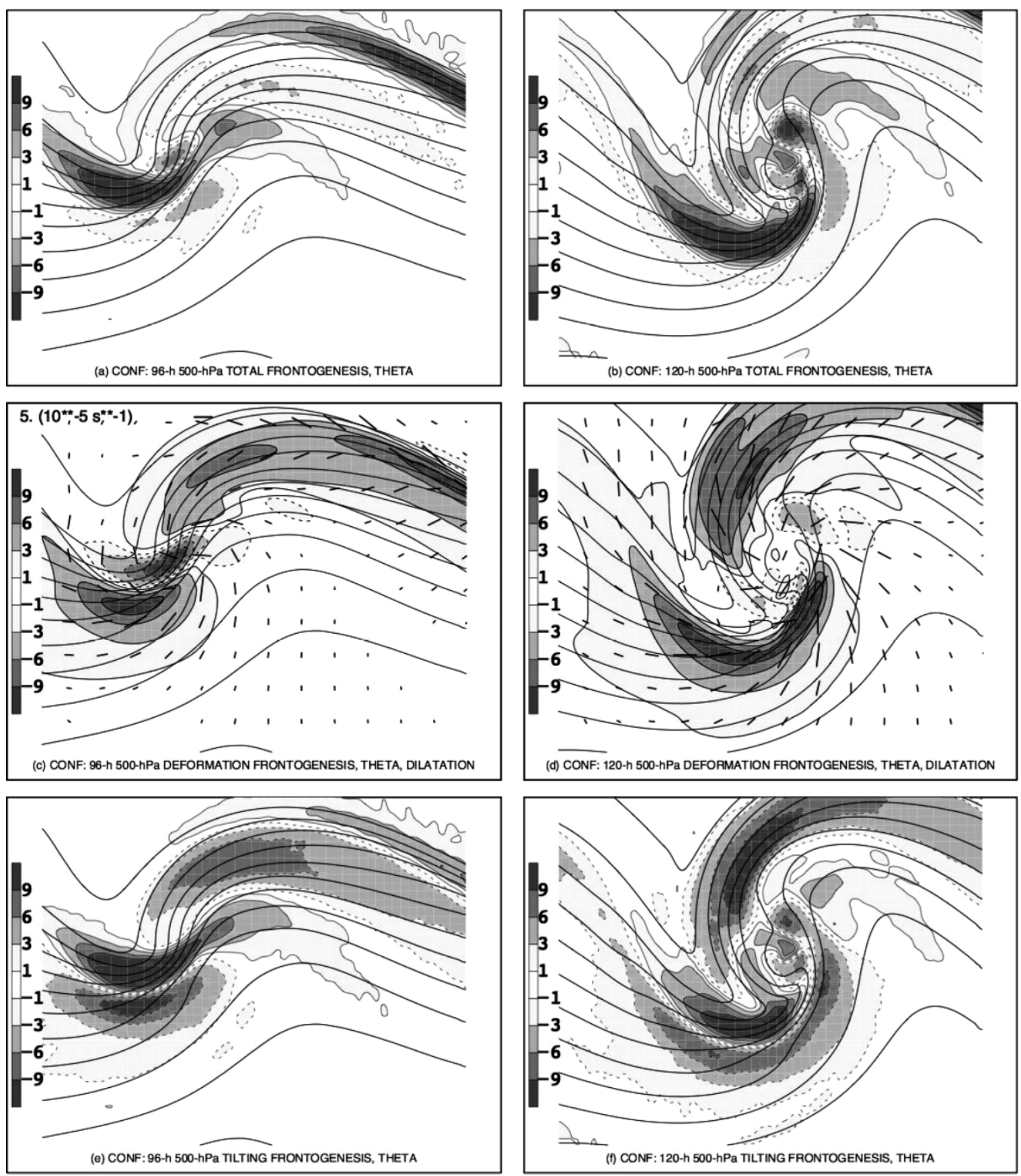

Figure 8. Evolution of a growing baroclinic disturbance in confluent background flow (CONF) at $96 \mathrm{~h} \mathrm{((a),} \mathrm{(c)} \mathrm{and} \mathrm{(e))} \mathrm{and} 120 \mathrm{~h}$ ((b), (d) and (f)). Only a portion of the computational domain is shown. Upper panels (a, b): $500 \mathrm{hPa}$ total frontogenesis $F_{3}$ (contoured and shaded according to scale in units of $10^{-1} \mathrm{~K}(100 \mathrm{~km})^{-1}(3 \mathrm{~h})^{-1}$, positive values solid and negative values dashed); potential temperature (solid lines every $4 \mathrm{~K}$ ). Middle panels (c, d): $500 \mathrm{hPa}$ potential temperature (solid lines every $4 \mathrm{~K}$ ); deformation frontogenesis $F_{\text {def }}$ due to total horizontal wind (contoured and shaded according to scale in units of $10^{-1} \mathrm{~K}(100 \mathrm{~km})^{-1}(3 \mathrm{~h})^{-1}$, positive values solid and negative values dashed); axes of dilatation of total horizontal wind (in units of $10^{-5} \mathrm{~s}^{-1}$, displayed axes of dilatation separated by $300 \mathrm{~km}$ (three grid-point spacings)). Lower panels (e, f): $500 \mathrm{hPa}$ potential temperature (solid lines every $4 \mathrm{~K}$ ); tilting frontogenesis $F_{\text {tilt }}$ (contoured and shaded according to scale in units of $10^{-1} \mathrm{~K}(100 \mathrm{~km})^{-1}(3 \mathrm{~h})^{-1}$, positive values solid and negative values dashed). 

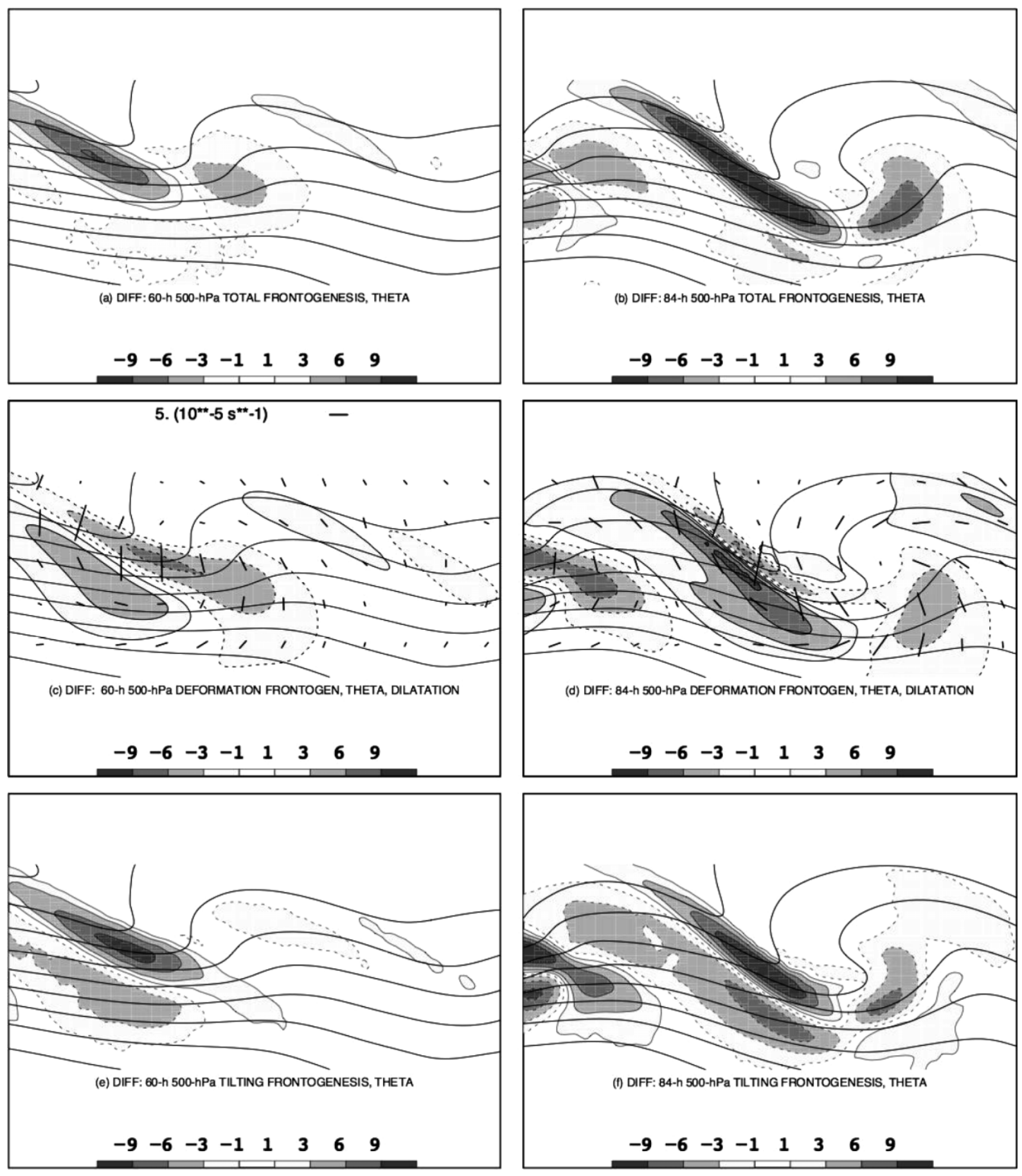

Figure 9. As Figure 8, but for growing baroclinic disturbance in diffluent background flow (DIFF) at $60 \mathrm{~h} \mathrm{((a),} \mathrm{(c)} \mathrm{and} \mathrm{(e))} \mathrm{and} 84 \mathrm{~h}((\mathrm{~b})$, (d) and (f)).

along the upper-level front, implying enhanced upperlevel frontogenesis.

By contrast, in DIFF, the upper-level front forms to the west of the trough (Figure 9), as in the classic cases of observed upper-level frontogenesis (e.g. Reed and Sanders, 1953; Newton, 1954; Reed, 1955; Newton, 1958; Shapiro, 1970; Sanders et al., 1991). At $60 \mathrm{~h}$, frontogenesis $F_{3}$ is dominated by tilting frontogenesis, as deformation frontogenesis is negative in the region where $F_{3}$ is positive (Figure 9 (a), (c) and (e)). By $84 \mathrm{~h}$, however, deformation frontogenesis has increased and overlaps regions of positive tilting frontogenesis (Figure 9 (b), (d) and (f)). Thus, tilting frontogenesis dominates early on, whereas both deformation and tilting frontogenesis become important later. As the upper-level front rounds the base of the trough, frontolysis due to both the deformation and the tilting terms weakens the eastern end of the front (Figure 9 (b), (d) and (f)). This case is similar to the northwesterly-flow case in diffluence presented by Schultz and Sanders (2002, figure 7), where tilting dominates over deformation. It differs from the cases presented by Bosart $(1970,2003)$ because 
frontolysis on the eastern side of the trough in DIFF is due to both deformation and tilting, whereas the cases discussed by Bosart (1970, 2003) feature frontolysis due to tilting but frontogenesis due to deformation. In DIFF, deformation and tilting frontogenesis extend along the length of the upper-level front, in contrast to the experiment of Rotunno et al. (1994), where there is no overlap between deformation and tilting frontogenesis at day 7 (Rotunno et al., 1994, figure 19) and overlap occurs only along the southernmost portion of the upper-level front in northwesterly flow (Rotunno et al., 1994, figure 20).

\section{Conclusions}

The purpose of this study is to discuss the factors affecting the life cycles of baroclinic waves: specifically, the role of the large-scale flow.

This study proffers two paradigms. In the first paradigm, across-jet (meridional, for zonally-oriented jets) barotropic shear is added to idealized-numerical-modelling studies of growing baroclinic waves to produce different life cycles. In the absence of barotropic shear, the resulting life cycle is similar to that of the Shapiro-Keyser cyclone model. When cyclonic barotropic shear is added, the resulting life cycle resembles that of the Norwegian cyclone model. When anticyclonic barotropic shear is added, the resulting life cycle resembles that of open-wave frontal waves. Despite several idealized-numerical-modelling studies demonstrating the relationship between across-jet barotropic shear and cyclone structure, quantitative observational evidence is still lacking.

In the second paradigm, along-jet (zonal, for zonallyoriented jets) variations in wind speed are considered to control the life cycles of baroclinic waves. Observational studies relate different cyclone structures and evolutions to confluence at jet-entrance regions or diffluence at jet-exit regions, both types of regions being favourable for cyclogenesis. In contrast to the first paradigm, idealized-numerical-modelling studies supporting these results are rare. Although Schultz et al. (1998) have performed non-divergent barotropic-model experiments with potential temperature as a passive tracer, the present study uses a primitive-equation baroclinic channel model. These two studies produce similar results, indicating that cyclones in flows with large-scale confluence produce Shapiro-Keyser-type cyclones while cyclones in flows with large-scale diffluence produce Norwegian-type cyclones. Background confluence stretches the cyclones and fronts in a zonal direction, favouring a strong warm front and the frontal T-bone pattern characteristic of the Shapiro-Keyser model. Furthermore, the advection of the strong warm-frontal temperature gradient around the cyclone favours the development of a bent-back front and eventual seclusion. Background diffluence stretches the cyclones and fronts in a meridional direction, favouring a strong cold front and the narrowing of the warm sector to form an occluded front.
Different evolutions of upper-level frontogenesis also occur in these different flow patterns. In the case of large-scale confluence, upper-level frontogenesis occurs primarily in the southwesterly flow on the eastern side of the large-scale trough, where frontogenesis is favoured downstream of the trough, as the flow is accelerated and stretched by the confluence. By contrast, in the case of large-scale diffluence, upper-level frontogenesis occurs primarily on the western side of the large-scale trough, where the upper-level vorticity maximum is slowing down and undergoing compaction because of the diffluence.

To date, the reigning paradigm for explaining the variability of the life cycles of extratropical cyclones has been the across-jet shear paradigm, best conceptualized by the LC1, LC2 and LC3 life cycles derived from idealized-modelling experiments (e.g. Thorncroft et al., 1993; Shapiro et al., 1999). The present paper argues that zonal variability in the jet stream (i.e. the along-jet paradigm) favours different cyclonic and frontal evolutions, in both the lower and the upper troposphere. We argue that there is abundant observational evidence linking cyclogenesis to the jet-entrance and jet-exit regions. Idealized-modelling experiments with both barotropic and baroclinic models, demonstrating the variability of cyclone structures and evolutions, also support the alongjet paradigm.

\section{Acknowledgements}

In 1996, following a suggestion by the first author, Prof. Heini Wernli performed idealized primitiveequation-model experiments showing the feasibility of the research presented in this paper. Although his work remains unpublished, we extend our deepest appreciation to Prof. Wernli for his inspiration, as well as for providing comments on an early draft of this manuscript. Discussions with Prof. Daniel Keyser helped improve the manuscript. Funding for the first author was provided by NOAA/Office of Oceanic and Atmospheric Research under NOAA-University of Oklahoma Cooperative Agreement NA17RJ1227, US Department of Commerce. Funding for the second author was provided by the National Science Foundation under grant ATM0203238 .

\section{References}

Bjerknes J. 1919. On the structure of moving cyclones. Gephys. Publ. 1(2): $1-8$.

Bjerknes J, Solberg H. 1922. Life cycle of cyclones and the polar front theory of atmospheric circulation. Gephys. Publ. 3(1): 3-18.

Bluestein HB. 1986. Fronts and jet streaks: A theoretical perspective. In: Mesoscale Meteorology and Forecasting, Ray PS (ed). American Meteorological Society: 173-215.

Bluestein HB. 1993. Synoptic-Dynamic Meteorology in Midlatitudes. Volume II: Observations and Theory of Weather Systems. Oxford University Press.

Bosart LF. 1970. Mid-tropospheric frontogenesis. Q. J. R. Meteorol. Soc. 96: 442-471.

Bosart LF. 2003. Tropopause folding, upper-level frontogenesis, and beyond. In: A Half Century of Progress in Meteorology: A Tribute 
to Richard Reed. Meteorological Monographs No. 53. American Meteorological Society: Boston, USA: 13-47.

Davies HC, Schär C, Wernli H. 1991. The palette of fronts and cyclones within a baroclinic wave development. J. Atmos. Sci. 48: $1666-1689$

Davis CA, Emanuel KA. 1991. Potential vorticity diagnosis of cyclogenesis. Mon. Weather Rev. 119: 1929-1953.

Dudhia J. 1993. A nonhydrostatic version of the Penn State-NCAR mesoscale model: Validation tests and simulation of an Atlantic cyclone and cold front. Mon. Weather Rev. 121: 1493-1513.

Evans MS, Keyser D, Bosart LF, Lackmann GM. 1994. A satellitederived classification scheme for rapid maritime cyclogenesis. Mon. Weather Rev. 122: 1381-1416.

Grell GA, Dudhia J, Stauffer DR. 1994. 'A description of the fifthgeneration Penn State/NCAR Mesoscale Model (MM5)'. NCAR Tech. Note NCAR/TN-398+STR. NCAR, PO Box 3000, Boulder, CO 80 307-3000, USA

Hartmann DL. 1995. A PV view of zonal flow vacillation. J. Atmos. Sci. 52: 2561-2576.

Hartmann DL, Zuercher P. 1998. Response of baroclinic life cycles to barotropic shear. J. Atmos. Sci. 52: 297-313.

Hines KM, Mechoso CR. 1993. Influence of surface drag on the evolution of fronts. Mon. Weather Rev. 121: 1152-1175.

Keyser D, Pecnick MJ. 1985. A two-dimensional primitive equation model of frontogenesis forced by confluence and horizontal shear. J. Atmos. Sci. 42: 1259-1282.

Keyser D, Shapiro MA. 1986. A review of the structure and dynamics of upper-level frontal zones. Mon. Weather Rev. 114: 452-499.

Keyser D, Pecnick MJ, Shapiro MA. 1986. Diagnosis of the role of vertical deformation in a two-dimensional primitive equation model of upper-level frontogenesis. J. Atmos. Sci. 43: 839-850.

Keyser D, Reeder MJ, Reed RJ. 1988. A generalization of Petterssen's frontogenesis function and its relation to the forcing of vertical motion. Mon. Weather Rev. 116: 762-780.

Kuo Y-H, Low-Nam S. 1994. 'Effects of surface friction on the thermal structure of an extratropical cyclone'. In: Proceedings, International Symposium on the Life Cycles of Extratropical Cyclones, vol. III, Grønås S, Shapiro MA (eds). Geophysical Institute, University of Bergen: Norway: 129-134.

Lackmann GM, Keyser D, Bosart LF. 1997. A characteristic life cycle of upper-tropospheric cyclogenetic precursors during the Experiment on Rapidly Intensifying Cyclones over the Atlantic (ERICA). Mon. Weather Rev. 125: 2729-2758.

Martius O, Schwierz C, Davies HC. 2007. Breaking waves at the tropopause in the wintertime Northern Hemisphere: Climatological analyses of the orientation and the theoretical LC1/2 classification. J. Atmos. Sci (accepted).

McCallum E, Norris WJT. 1990. The storms of January and February 1990. Meteorol. Mag. 119: 201-210.

Miller JE. 1948. On the concept of frontogenesis. J. Meteorol. 5: $169-171$.

Nakamura N. 1993. Momentum flux, flow symmetry, and the nonlinear barotropic governor. J. Atmos. Sci. 50: 2159-2179.

Newton CW. 1954. Frontogenesis and frontolysis as a threedimensional process. J. Meteorol. 11: 449-461.

Newton CW. 1958. Variations in frontal structure of upper level troughs. Geophysica 6: 357-375.

Petterssen S. 1936. Contribution to the theory of frontogenesis. Gephys. Publ. 11(6): 1-27.

Reed RJ. 1955. A study of a characteristic type of upper-level frontogenesis. J. Meteorol. 12: 226-237.

Reed RJ, Sanders F. 1953. An investigation of the development of a mid-tropospheric frontal zone and its associated vorticity field. $J$. Meteorol. 10: 338-349.
Reeder MJ, Keyser D. 1988. Balanced and unbalanced upper-level frontogenesis. J. Atmos. Sci. 45: 3366-3386.

Rotunno R, Skamarock WC, Snyder C. 1994. An analysis of frontogenesis in numerical simulations of baroclinic waves. J. Atmos. Sci. 51: 3373-3398.

Rotunno R, Skamarock WC, Snyder C. 1998. Effects of surface drag on fronts within numerically simulated baroclinic waves. J. Atmos Sci. 55: 2119-2129.

Sanders F, Bosart LF, Lai C-C. 1991. Initiation and evolution of an intense upper-level front. Mon. Weather Rev. 119: 1337-1367.

Schultz DM, Doswell CA. 1999. Conceptual models of upper-level frontogenesis in south-westerly and north-westerly flow. $Q . J . R$. Meteorol. Soc. 125: 2535-2562.

Schultz DM, Sanders F. 2002. Upper-level frontogenesis associated with the birth of mobile troughs in northwesterly flow. Mon. Weather Rev. 130: $2593-2610$.

Schultz DM, Keyser D, Bosart LF. 1998. The effect of large-scale flow on low-level frontal structure and evolution in midlatitude cyclones. Mon. Weather Rev. 126: 1767-1791.

Shapiro MA. 1970. On the applicability of the geostrophic approximation to upper-level frontal-scale motions. J. Atmos. Sci. 27: 408-420.

Shapiro MA. 1981. Frontogenesis and geostrophically forced secondary circulations in the vicinity of jet stream-frontal zone systems. $J$ Atmos. Sci. 38: 954-973.

Shapiro MA, Keyser D. 1990. 'Fronts, jet streams and the tropopause'. In: Extratropical Cyclones, Erik Palmén Memorial Volume, Newton CW, Holopainen EO (eds). American Meteorological Society: Boston, USA: 167-191.

Shapiro M, Wernli H, Bao J-W, Methven J, Zou X, Doyle J, Holt J, Donall-Grell E, Neiman P. 1999. 'A planetary-scale to mesoscale perspective of the life cycles of extratropical cyclones: The bridge between theory and observations'. In: The Life Cycles of Extratropical Cyclones, Shapiro MA, Grønås S (eds). American Meteorological Society: Boston, USA: 139-185.

Shapiro MA, Wernli H, Bond NA, Langland R. 2001. The influence of the 1997-99 El Nino Southern Oscillation on extratropical baroclinic life cycles over the eastern North Pacific. Q. J. R. Meteorol. Soc. 127: 331-342.

Simmons A. 1999. 'Numerical simulations of cyclone life cycles'. In: The Life Cycles of Extratropical Cyclones, Shapiro MA, Grønås S (eds). American Meteorological Society: Boston, USA: 123-137.

Simmons AJ, Hoskins BJ. 1978. The life cycles of some nonlinear baroclinic waves. J. Atmos. Sci. 35: 414-432.

Sinclair MR, Revell MJ. 2000. Classification and composite diagnosis of extratropical cyclogenesis events in the southwest Pacific. Mon Weather Rev. 128: 1089-1105.

Thompson WT. 1995. Numerical simulations of the life cycle of a baroclinic wave. Tellus 47A: 722-732.

Thorncroft CD, Hoskins BJ, McIntyre ME. 1993. Two paradigms of baroclinic-wave life-cycle behavior. $Q$. J. R. Meteorol. Soc. 119: $17-55$.

Wernli H, Fehlmann R, Lüthi D. 1998. The effect of barotropic shear on upper-level induced cyclogenesis: Semigeostrophic and primitive equation numerical simulations. J. Atmos. Sci. 55: 2080-2094.

Wernli H, Shapiro MA, Schmidli J. 1999. Upstream development in idealized baroclinic wave experiments. Tellus 51A: 574-587.

Young MV. 1995. Types of cyclogenesis. In: Images in Weather Forecasting, Bader MJ, Forbes GS, Grant JR, Lilley RBE, Waters AJ (eds). Cambridge University Press: 213-286.

Zhang F. 2004. Generation of mesoscale gravity waves in uppertropospheric jet-front systems. J. Atmos. Sci. 61: 440-457. 